en Galicia y Portugal en los siglos xilı y xiv, no hay duda de que se deba a un cruce con tragar. Sabido es que una voz importada, de gama semántica fluctuante y amenazada por el poderoso neologismo passar, sucumbe más fácilmente a la contaminación que una voz autóctona y libre de presión:":

University of California.

YAKOV MALKIEL

\title{
OTRA VERSIÓN DE "SOBRE NEVADOS RISCOS LEVANTADO..."
}

Seis son las versiones hasta hoy conocidas de la famosa égloga "Sobre nevados riscos levantado...": I) la del Parnaso español de López de Sedano, t. 4, Madrid, $177^{6}$ (de donde pasó a las Poesías de Francisco de Figueroa, ed. Fernández Estala, Madrid, 1804 , al t. 42 de la $B A A E E$ y a la nueva ed., por González. Palencia, de las Poesias de Figueroa, Madrid, 1943); 2) la de Poesias del siglo xvi, ms. 3968 de la B. N. M.; 3) la de Ilores de varia poesía recopiladas en México en 1577, y copia de Paz y Mélia, mss. 2979 y 7982 de la B. N. M.; 4) la de Obras de Mendoza, ms. $425^{6}$ de la B. N. M.; 5) la de Books of poems in Spanish verse, ms. 189 de All Souls College (Oxford); 6) la de Poesias de Pedro Lainez, ms. 68 de la Biblioteca del Duque de Gor (Granada).

La atribución a Francisco de Figueroa, que ha predominado durante mucho tiempo, carece de fundamento sólido. Con la edición de las Poesias de Pedro Lainez por A. Marín Ocete (Granada, 1950) se ha empezado a dudar seriamente de esa atribución, pues la égloga se encuentra, entre otras obras auténticas de Laínez, en un manuscrito granadino (Gor, 68) de alta autenticidad, aunque no autógrafo. Basado en esto, y además en un análisis estilístico, JoAQuín de EnTrambasaguas, en su edición de las Obras de Pedro Laynez (Madrid, 1951), se inclina decididamente por este poeta. Los argumentos en favor de Laínez se pueden corroborar con otras consideraciones. Ya Crawford indicó que el modelo de "Sobre nevados riscos levantado..." es una égloga del

$\because:$ No comprendo cómo Meyer-Lübke clasifica tragar como derivado de $\mathrm{t} r$ a h e re (REV S $_{11}$ ), negándose a la vez a subordinarlo a ${ }^{*} \mathrm{t}$ ra hicā re $\left(88_{4} 1 a\right)$. J. SARoïhnNDy, "Gloses catalanes de Munich [de hacia 1400]", $R F, 23$ (1907), 251, atribuye análogamente cat. ant. trangolir $=$ lat. sorbo (f. $27 \mathrm{v}^{\circ}$ II) a cruce de tragar y engullir; este biltimo, a su vee, podría explicarse por cl contacto de *i ngullāre (que presuponen it. ingollare. fr. engouler, prov. engolar) con el antiquísimo verbo,

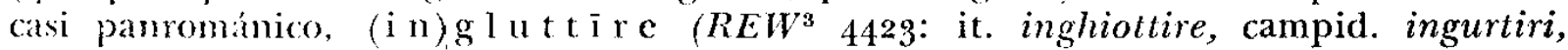
fr. engloutir, cat. englulir, etc; agrégucse lat. tardio tră $\mathrm{nsglut}$ i r c, que refleja

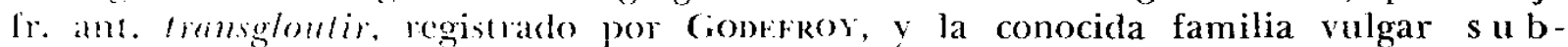
gluti-ius, -ió, *-iāre, fuente de sollozar). Ingullāre, por su parte, poslula un cruce esporidico de gula 'garganta' con collum 'cuello' (cf. esp. degollar < dēcollăre), en favor del cual abogan además tosc. ingollire (Luca) y esp. gollele. gollizo. A cat. ant. trangolir se accrca marcadamente can. trangulir, comer a lrangullones 'engullir rápidamente' (L. y A. Millares). Lo que hace plausible lales cadenas de cruces, que en otras condiciones deberían inspirar desconfianza, es el carícter altamente expresivo de todo este grupo semántico. La coexistencia de g l u t tó y g lü tó ya pone de manifiesto dicho expresivismo en latín. 
quattrocentista Tebaldeo $^{1}$. Ahora bien, este mismo poema italiano es imitado en otra obra indiscutible de Laínez, "Cerca de aquella dura y clara fuente..."; no sólo la utilización del mismo modelo, sino también "las características reiteraciones de expresión" (ENTrambasaguas, ed. cit., t. 1, p. 230), que tan notables son en la obra de Laínez, confirman la validez de la atribución. Hay más: en su imitación, Laínez llega a veces hasta el plagio, lo que nunca ocurre en el "divino" Figueroa, poeta de más acendradas dotes artísticas.

A las versiones ya citadas podemos añadir ahora otra contenida en el códice magliabechiano VII-353 de la Biblioteca Nazionale de Florencia, ff. $182 \mathrm{v}^{\circ}-188 \mathrm{r}^{\circ}$, gruesa antologia compuesta principalmente de obras españolas. El copista da a nuestro poema este título: "Estancias elegantes". Observamos en el texto varias alteraciones del orden de las estrofas. Hay asimismo numerosas e importantes variantes, lo cual nos impicle establecer una filiación clara con ninguna de las versiones que hemos enumerado ${ }^{2}$. He aquí la versión del ms. magl. VII-353:

\section{ESTANCIAS ELEGANTES}

Sobre neuados riscos leuantado, cerca del Tajo, está vn lugar sombrío, en el rigor del cielo tan templado, quan fresco en la saçón del [se]co estío, adonde de tristeça acompañado al son del agua del corriente río, tan dulcemente Tirsi se quexaua, que a los duros peñascos ablandaua.

Mil veces de morir determina[n]do, los ojos enclavados en el cielo, y su ventura triste lamentando con lágrimas regando el duro suelo, $\tan$ ardientes suspiros arrancando, que encendieran el más elado ielo, resistir no pudiendo a dolor tanto ansí soltó la rienda al duro canto:

«Después que de mis ojos se alexaron los que la luz del sol vueluen oscura, ni yo puedo viuir, pues me dexaron, 20 ni quiero, aunque pudiese, tal locura; y pues me dexan por lo que lleuaron dolor terrible, eterna desuentura mis males y tristíssimos cuydados, llorad sin descansar, ojos cansados.

»Mi Fili, el bien sin ti es todo incierto que no podrá creello quien lo viere;

1 J. P. W. Crawford, "The source of a pastoral Eclogue attributed to Fancisco de Figueroa", $M L N, 35$ (1920), 438-439.

2 Véase el registro de las variantes en la ed. de Marln OCrTr, pp. 10,-112. y en la de Entrambasaguas, t. 2, pp. 368-373. En el texto que damos a continuación hemos respetado la ortografía del original, pero modernizando la acentuación y la puntuación. No hemos hecho más corrección que la del v. 4, donde, por descuido del copista, se lee "del fresco estío" en vez de seco, como aparece en las demás versiones. 
la esperança dudosa, el dolor cierto, según la fuerça con que amor me hiere; mas el que por tu mano ha de ser muerto no procure viuir, pues assí muere.

iAy, remedios terribles y escusados!

Llorad sin descansar, ojos cansados.

* Ya veys cómo sin Fil(l)i, húmidos ojos, sus rayos de oro cubre Apol(l)o al día, bien veys, mi Fili, ya tristes despojos de quanto el cielo acá sustenta oy día, y veys cómo produce en cambio abrojos quien olorosas flores producía, secos ríos, los campos agostados.

40 Llorad sin descansar, ojos cansados.

«Pues no puedo seguirte, jo Fili mía! siempre te seguirá mi pensamiento; morir quiero mil veces cada día antes que padecer tan gran tormento; que quando de tu amor tube osadía tan cierto y breve vi mi perdimiento, que me dixeron luego allí mis hados: Llorad sin descansar, ojos cansados,

`Durmiendo acaso vn día en la floresta,

$5^{\circ}$ Vencido del dolor, Fili, soñaua que en el ardor ardiente de la siesta en la sombra de vn sauce me hallaua; mas fortuna, en mi daño firme y presta, me dio luego a entender que me engañaua; y pues mis bienes son bienes soñados, llorad sin descansar, ojos cansados.

"Estaua yo diciendo: Este no es sueño, que el sueño es cosa vana y mentirosa, incierto su placer breve y pequeño,

6o y en él no ay cosa tal ni tan hermosa; también, por otra parte, si no es sueño, ¿cómo está aora Fili tan piadosa? ¡Ay, desengaños por mi mal hallados! Llorad sin descansar, ojos cansados.

^Y viéndome en tal término llegado, sin culpa culpo al cielo y mi destino. Mas del bien que mis ojos han mirado en un hermoso rostro y ser diuino, de auerme a cierta muerte condenado quexarme aora al cielo es desatino; y pues en el mirar fuistes osados, llorad sin descansar, ojos cansados.

»No lloro solamente mi partida, aunque es mal que da muerte solamente; lloro ver la esperança consumida en quien siempre el deseo es más ardiente; lloro tu rigurosa despedida, cuyo rigor terrible el alma siente, y los males que encubro desusados;

8o llorad sin descansar, ojos cansados. 
هual la agua al río, al campo la verdura, la mucha blanca leche a mi ganado, quanto le alegra el monte la espessura, a la tierra la yerua y flor al prado, tal es a estos mis ojos tu figura; y pues de verle estoy desconfiado, por ríos, sierras, montes, tierras, prados, llorad sin descansar, ojos cansados.

„Ya las ninphas del Tajo y su ribera

9o lloran tu doloroso apartamiento, pues no ay $\sin$ ti en la tierra primauera ni en las seluas y montes ornamento; la casta diosa, desdeñosa y fiera esparcido el cabello al fresco viento, no persigue ya corços ni venados. Llorad sin descansar, ojos cansados. "En tal vniversal pena y estraña, muy mal podía venir Tirsi contento: de amargo llanto el rostro y ojos baña, $100 \mathrm{y}$ aun le parece corto el sentimiento. Ya no me vale, Fili, fuerça y maña para tener sin verte sufrimiento, y ansí serán mis días acauados. Llorad sin descansar, ojos cansados.

"Si no es determinado que yo muera en tan grande dolor y desuentura, si no es llegada la ora postrimera de aquella noche eternamente oscura, veys aquí el valle ameno y la ribera,

110 el fértil prado, ieruas y frescura, lugares algún tiempo de ti amados. Llorad sin descansar, ojos cansados. `Quién os a puesto, Fili, en tal estado? Que descanso será mi muerte cierta, y no sé cómo tanto se ha tardado, pues mi esperança está del todo muerta; ausente muero, triste y desamado, en parte solitaria y tan desierta do sé serán mis uesos enterrados.

120 Llorad sin descansar, ojos cansados.

"iAy, que no entiendo ya dó me a traýdo el dolor de no verte, Fili mía!

No sé sino que muero y e viuido después que no te vi con alegría; el fin de mi jornada es cumplido, la oscura noche viene antes que el día, mis términos postreros son llegados. Llorad sin descansar, ojos cansados».

Aquí dio fin al llanto y a la vida

130 el sin ventura Tirsi mal logrado; el triste pecho de cruel herida con agudo cuchillo atraucsado, quiriendo antes de sí ser omicida que sufrir el dolor de su cuydado; 
la verde yerua por allí sembrada tiñó su roja sangre en colorada.

Damón, su caro amigo, que escuchando estaua el dulce canto doloroso, salió de donde estaua, imaginando

140 el caso lamentable y congoxoso.

Al sin ventura Tirsi vio espirando, teñido con su sangre, polvoroso.

El nombre nuebo amado repetía y con suspiros tristes le decía:

"Es ésta la alegría, ay, Tirsi amado, que le queda a Damón, tu firme amigo: ver tu funesto fin arrebatado a quien tanto te amaua por testigo? ¿Por qué no me auisaste de tu estado, $15^{\circ}$ por qué no me lleuaste allí contigo, y por qué, pues del todo me olvidaste, los últimos abraços me negaste?

"¿Qué se dirá de ti, siendo sabido que tú has muerto con tu propria mano, o amado Tirsi, por Damón tenido por más que amigo y natural hermano, siendo el pastor más sauio y entendido de toda esta ribera y verde llano, y de hermosas ninphas siempre amado, I6o de las hermanas nueue celebrado? " ¿De qué te sirue auer sido excelente de plantar vides y sembrar ceuadas, en guardar de los lobos diligente las tiernas ouejuelas descuydadas, y auer exercitado cuerdamente contiendas pastoriles tan dudadas? Si el fin es el que loa el curso humano, ¿por qué contigo fuiste tan tirano?

" $\mathrm{Tu}$ sanguinoso cuerpo bien lauado

170 con agua clara, embuelto en varias flores debaxo vn blanco mármol encerrado pondré donde se entallen tus loores. $Y$ no quiero a tu muerte, Tirso amado, ni a tus obsequias convocar pastores, sino quedarme aquí en esta ribera lamentando tu fin hasta que muera.

-Y aunque escrivirte versos es locura, forçado del dolor que el alma siente de ver ya buelta en tierra tu figura

180 en tus primeros años crudamente, y en la memoria de tu desuentura por que suenc tu mal de gente en gente, en la corteça dura deste pino poner este epitafio determino:

»Debaxo deste mármol sepultado yace el más sin ventura y más dichoso pastor que apacentó jamás ganado riueras deste río caudaloso; 


$$
\begin{aligned}
& \text { en morir tan temprano desdichado, } \\
& \text { 190 en amar altamente venturoso; } \\
& \text { él mismo se dio muerte de afligido; } \\
& \text { la causa yo no sé, si Amor [no] a sido». }
\end{aligned}
$$

Joseph G. FUCilla

Northwestern University.

\section{LOS "ERRORES COMUNES": PERO MEXIAA Y EL P. FEIJOOO}

La obra toda de Feijóo está destinada a combatir los "errores comunes". Desde el prólogo del Teatro crítico se afirma esta intención: "De suerte que cada tomo, bien que el designio de impugnar errores comunes uniforme, en cuanto a las materias parecerá un riguroso misceláneo. El objeto formal será siempre uno. Los materiales precisamente han de ser muy diversos".

Juan Marichal, en su agudo ensayo intitulado "Feijóo y su papel de desengañador de las Españas", $N R F H, 5$ (1951), 313-329, demostró que estos "errores comunes" cumplen la misma función que las "soñadas invenciones" en la imaginación de don Quijote. Feijóo alza estos gigantes para arremeter contra ellos; los crea para poder cumplir su misión de Desengañador. Como dice el crítico citado: "El móvil literario real de Feijóo no es tanto desengañar a los españoles como explayar su personalidad por el vasto campo de los errores comunes... Su fantasía quizá, pero más aún su afán por realzar su personalidad, se recreaba con todas las creencias absurdas que él atribuía al pueblo español, pero que muchas veces sólo existían en los libros. Feijóo vio quijotescamente muchos gigantes donde no los había para poder proyectar sobre el fondo de sus sombras amenazadoras la grandiosidad señorial de su figura de Desengañador de las Españas" (p. 317).

Marichal vio, con mucho acierto, cómo Feijóo se hace a sí mismo, se proyecta en su gran creación: la de su personalidad como Desengañador de las Españas. Su estudio es el punto de partida de estas páginas, y a él remito al lector. Las premisas necesarias de que parto, en lo que atañe a Feijóo, se hallarán en su articulo.

Pero antes de intentar una nueva vía de aproximación a la actitud de Feijóo frente al Error Común, se me impone un rodeo comparativo, y espero que aclaratorio. Toda definición entraña, hasta cierto punto, una serie de comparaciones tácitas previas. Por consiguiente, como paso preliminar necesario en el asedio de Feijóo y el error común, estudiaré a grandes rasgos la actitud de un antecesor, cuya obra, en su tiempo, gozó de tanta o mayor popularidad que la del benedictino en el suyo. Me refiero a Pero Mexía y su Silva de varia lección, verdadero Teatro acrítico del siglo xvi.

Al contrario de lo que sucede con alguno de sus coetáneos (Antonio de Guevara, por ejemplo), la obra de Mexía todavía no ha sido alcanzada por el revisionismo histórico de las últimas décadas ${ }^{1}$. Sin embargo, el espigueo en sus libros ofrece algunos resultados interesantes.

1 Lo más reciente que conozco sobre el humanista sevillano son las páginas que le dedica M. Batallion, Erasmo y España, México, 1950, t. 2, pp. 242-243, 255, y el 